\title{
DESIGN AND FABRICATION OF GAMMA-TYPE STIRLING ENGINE WITH ROTARY DISPLACER
}

\author{
Ajay Ashok ${ }^{1}$, Arundas $\mathrm{S}^{\mathbf{2}}$, Bestin Varghese ${ }^{3}$, Ajithkumar.K.T $\mathbf{T}^{\mathbf{4}}$ \\ ${ }^{1}$ Student, Department Of Mechanical Engineering, B.T.C College Engineering \& Technology, Ernakulam, India \\ ${ }^{2}$ Student, Department Of Mechanical Engineering, B.T.C College Engineering \& Technology, Ernakulam, India \\ ${ }^{3}$ Student, Dept. of Mechanical Engineering, B.T.C College Engineering \& Technology, Ernakulam, India \\ ${ }^{4}$ Assistant Professor, Dept. of Mechanical Engineering, B.T.C College Engineering \& Technology, Ernakulam, India
}

\begin{abstract}
At present, ecology is of primary concern. Looking for savings is an equally important factor forcing to implement innovative technologies. Many of industrial plants, devices and installations, heat energy is lost. An innovative solution is the use of Stirling engines for the use of waste heat energy. They can operate with relatively small temperature differences. Among the three configurations such as the alpha, beta and gamma types, the gamma type is very economical and simple in fabrication. So that we have decided to fabricate a gamma-type Stirling engine.

We designed and fabricated a Gamma-type Stirling engine with rotary displacer for utilizing the waste heat in a cost for a better economy. Prior to the fabrication, the engine was modeled by using Autodesk Inventor. We used the parts of dumped machines for fabricating the Engine. The power piston which is used to extract the power from displacer cylinder is the compressor of a refrigerator. We have designed the engine to utilize the waste heat from the steam-boiler in our college. Similarly all the other components along with frame are dispatched from many other waste machines. This simple Engine can be easily fabricated and can be used for house-hold applications.
\end{abstract}

Keywords: Stirling engine, alpha, beta and gamma configurations, rotary displacer, waste heat management.

\section{INTRODUCTION}

The Stirling Engine is one of the hot air engines. It was invented by Robert Stirling (1790-1878) and his brother James. There are three major configurations in stirling engine such as Alpha type, Beta type, and Gamma type. Gamma-type engine which is cheaper and simple in fabrication. Stirling engine with Rotary displacer Gamma type configuration is a rare topic. We have decided to design and fabricate this type of Stirling engine which works with waste heat as input. Usually the temperature of waste heat is high, the heat recovery process possess high quality and will be cost effective.

\subsection{Stirling Cycle}

The Stirling engine fixed mass of gas called the "working fluid" such as gases like air, hydrogen or helium. The working principle is the thermal expansion and contraction of this fluid due to a temperature differential. So the ideal Stirling cycle consists of four thermodynamic process acting on the working fluid: Each one of which can be separately analyzed:

1-2: isothermal compression process

2-3: isochoric displacement process

3-4: isothermal expansion processes

4-1: isochoric displacement process
The efficiency of Stirling cycle is same as that of Carnot cycle efficiency when both are working with the same temperature limits.
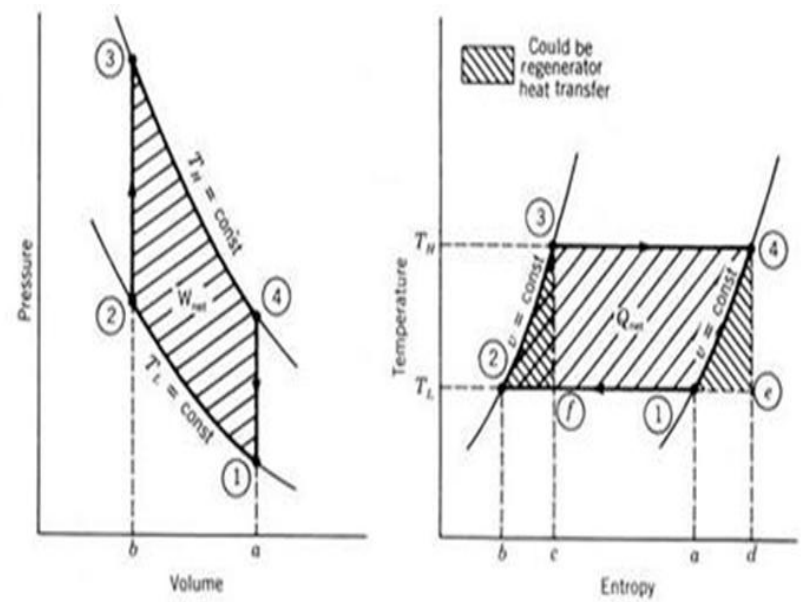

\section{GAMMA TYPE STIRLING ENGINE WITH ROTORY DISPLACER}

The main component of Gamma type Stirling engine is the rotary displacer and its characteristics are as follows. Adoption of a rotary displacer over a reciprocating one provided two major advantages. They are necessity of reduced power in each working cycle and increased 
flexibility of design. A rotary displacer, at normal operating condition, exerts thrust and radial loads only. The main objectives of our project are as follows:

1. Design and fabrication of a low cost Stirling engine

2. Estimation of the cost and duration of project

3. Design of the various components for the engine

4. Fabrication

5. Testing

6. Documentation

\subsection{Scope of the Project}

The Stirling engine can be used as an efficient engine in future due to its advanced characteristics as follows;

1. It is an external combustion engine with low emission and less noise and very economical

2. Conventional fuels and renewable energy sources can be used to power the engine

3. The engine will also work with waste heat such as the heat from boilers, furnaces, etc.

4. There is no need for the continuous supply of the working fluid.

\subsection{D Modeling of the System using Inventor}

The modeling of the engine was done in the designing software, Autodesk Inventor 2013. Following are the order in which the drawing is completed:

- $\quad$ Displacer piston and cylinder assembly

- $\quad$ Power piston and cylinder assembly.

- Pneumatic tube.

- $\quad$ Final assembly of the engine
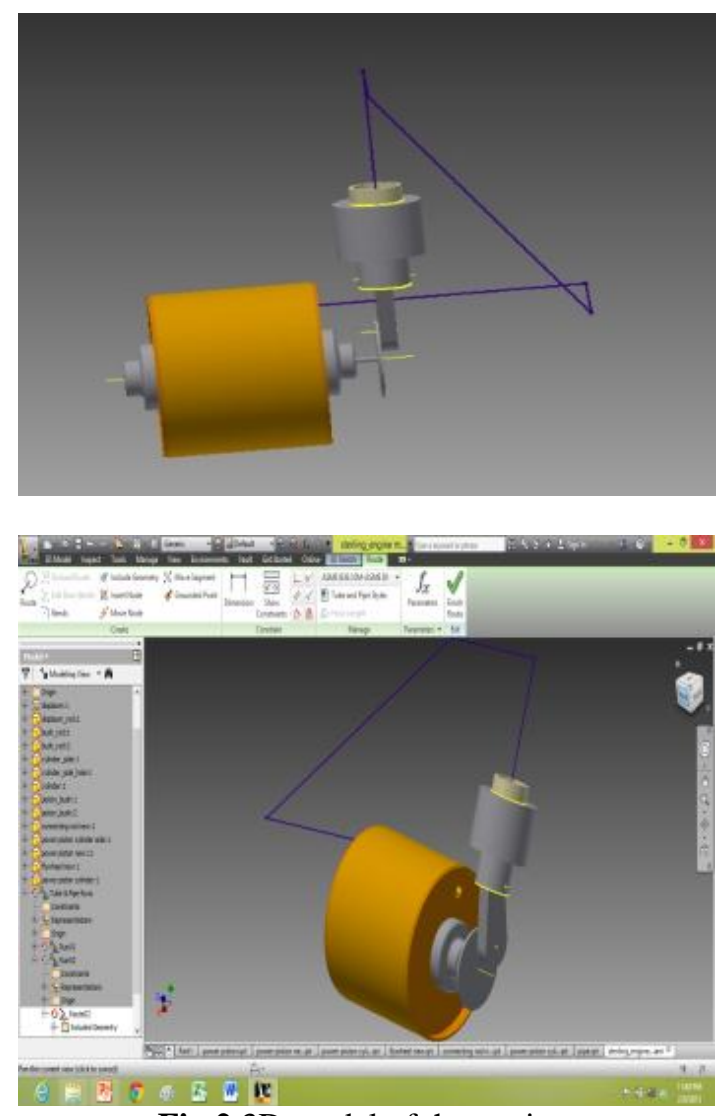

Fig.2 3D model of the engine

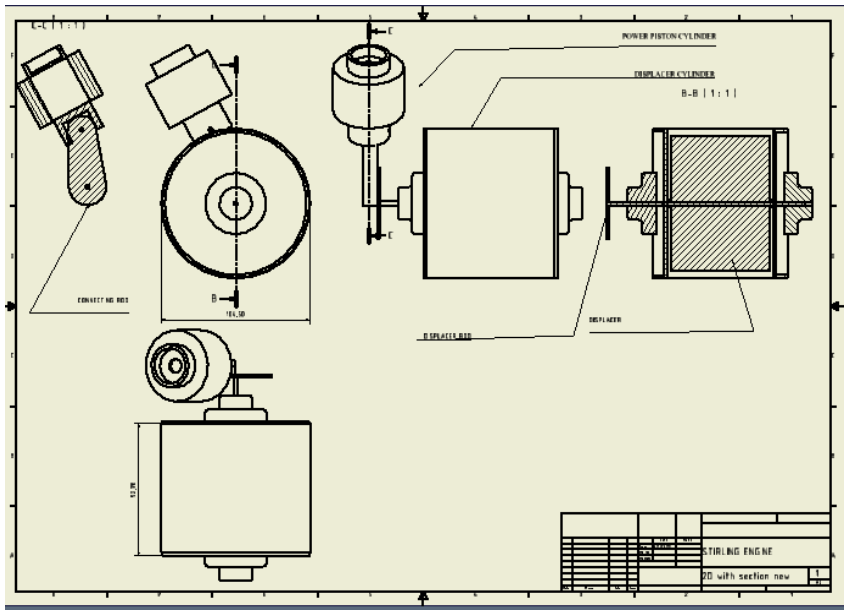

Fig.2 2D Sectional Drawing of Engine

\section{DESIGN CALCULATIONS}

We assume that only the pressure force and the weights of elements are having a major role on the output power of the engine. The pressure force is due to the sudden cooling of the expanded hot air while it reaches the cool side of the displacer - cylinder. A gas at low pressure is compressed and the pressure is increased when it was cooled. Its major advantage that it will not consume any power from the engine and its contribution of weight to the engine is necessary for obtaining the required output power.

We have, output power,

$$
\mathrm{P}=\frac{2 \pi \mathrm{NT}}{60}
$$

Where,

$\mathrm{N}=$ Speed of crank shaft $=150 \mathrm{rpm}$ (approx.)

$\mathrm{T}=$ Torque in $\mathrm{N}-\mathrm{m}$

To find the torque,

$$
T=\left[\left(\frac{P}{A}\right)+F\right] \times L
$$

$\mathrm{P} / \mathrm{A}=$ force exerted by the power piston $A=$ Area of the cylinder of power piston $F=$ Force due to the masses of flywheel, crank shaft, connecting rod and power piston in Newton $L=$ Length of crank shaft $=20 \mathrm{~cm}=0.2 \mathrm{~m}$

We cannot simply predict the pressure force directly and it is very much difficult to assume its value.

So the design calculations are made by considering only the force due to weights of following elements.

Mass of flywheel $=500$ gram

Mass of crank shaft $=50$ gram

Mass of connecting rod $=150$ gram

Mass of power piston $=150$ gram

Total mass of four elements $=500+50+150+150=850$ gram Force, $\mathrm{F}=\mathrm{m} \times \mathrm{g}=0.850 \times 9.81=8.3385 \mathrm{~N}$ 
Torque, $\mathrm{T}=\mathrm{F} \times \mathrm{L}=8.3385 \times 0.2=1.6676 \mathrm{~N}-\mathrm{m}$

Assume $\mathrm{N}=150 \mathrm{rpm}$

Therefore, output power,

$$
\begin{aligned}
P= & \frac{2 \pi N T}{60}=\frac{(2 \pi \times 150 \times 1.6676)}{60} \\
& =26.19617 \text { watts }
\end{aligned}
$$

The obtained power output will increase while considering the force due to pressure on power piston. We could expect a minimum power output as 50 watts.

\subsection{Specifications of Components}

\section{Displacer Piston}

Material M-seal with aluminum composite panel

Diameter $\quad 9.5 \mathrm{~cm}$, Length $7 \mathrm{~cm}$
2. Displacer Cylinder:
Material - Aluminum
Diameter
$10.5 \mathrm{~cm}$,
Length $\quad 9 \mathrm{Cm}$

3. Cylinder Side

Material Aluminum: Diameter $\quad 10.4 \mathrm{~cm}$

4. Displacer Piston Rod Material - Cast iron

Diameter $\quad 2.5 \mathrm{~cm}$, Length $14 \mathrm{~cm}$

$\begin{array}{lll}\text { 5. Cylinder for Power Piston: } & \text { Material - Cast iron } \\ \text { Diameter } & 2.9 \mathrm{~cm}, & \text { Length }\end{array}$

6. Power Piston

Material Cast iron

Length $2 \mathrm{~cm}$

$\begin{array}{ll}\text { Diameter } & 2.2 \mathrm{~cm} \\ \text { Weight } & 150 \text { gram }\end{array}$

7. Connecting Rod

Material Cast iron

Weight

150 gram

Diameter of big end

$2.65 \mathrm{~cm}$

Diameter of small end

$2 \mathrm{~cm}$

\section{Flywheel}

Diameter

$10.5 \mathrm{~cm}$

Material - MS disc

\subsection{Construction}

Displacer Cylinder Assembly- The displacer cylinder assembly consists of rotary displacer, hole for pneumatic tube, flywheel, shaft, bearing and plates which separates the hot side and cold side of the displacer cylinder. The main component is the rotary displacer which is made up of body filler material was coated over a nylon rod and OHP sheet. After drying it is to be machined on a lathe. The remaining portions are also be filled and cut a chamfered surface and made a solid shape. Two holes of $10 \mathrm{~mm}$ diameter are provided for the placing of the shaft of the displacer. At first the displacer cylinder was made up of tin material. The displacer was to be placed in the cylinder using bushes provided on both sides and at one end there was a hole for placing the connector for attaching a pneumatic pipe for the flow of air.

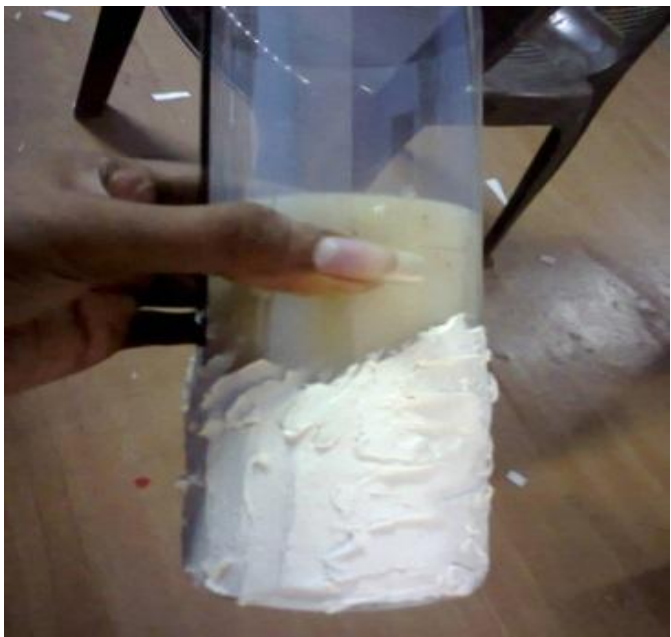

1. Nylon rod

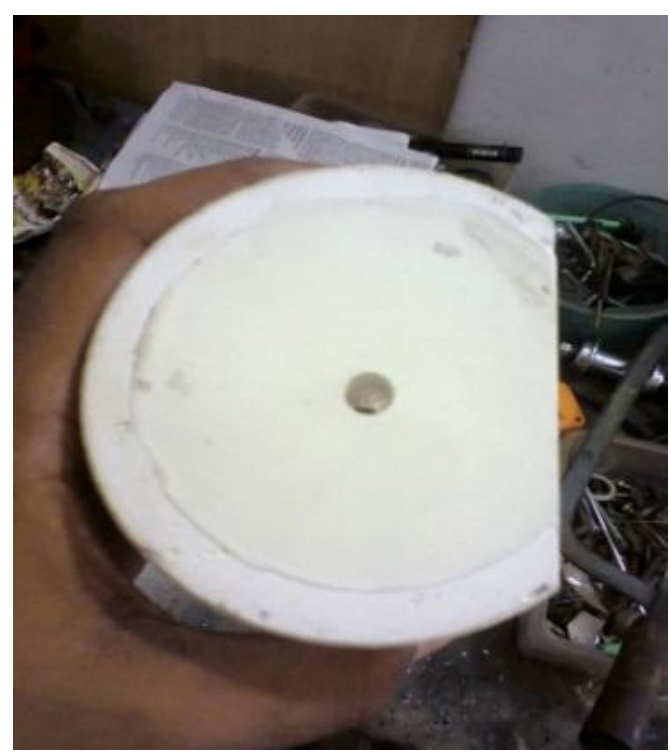

2. Rotary Displacer of Body Filler Material

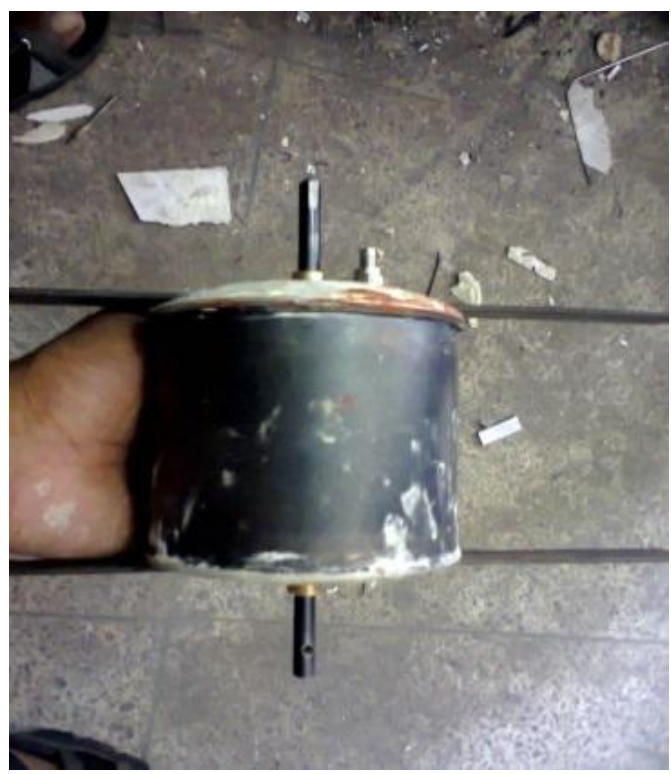




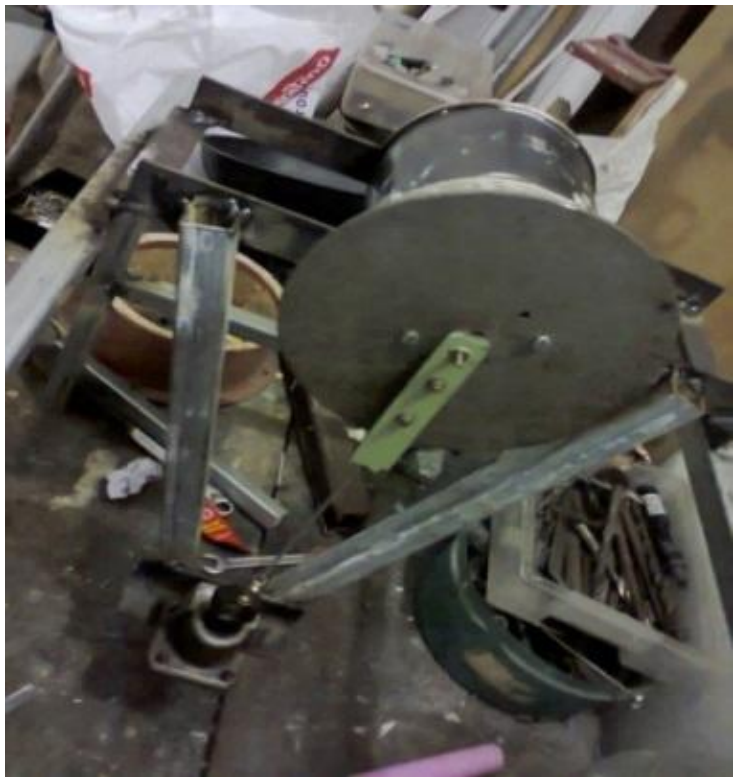

Displacer cylinder made up of tin
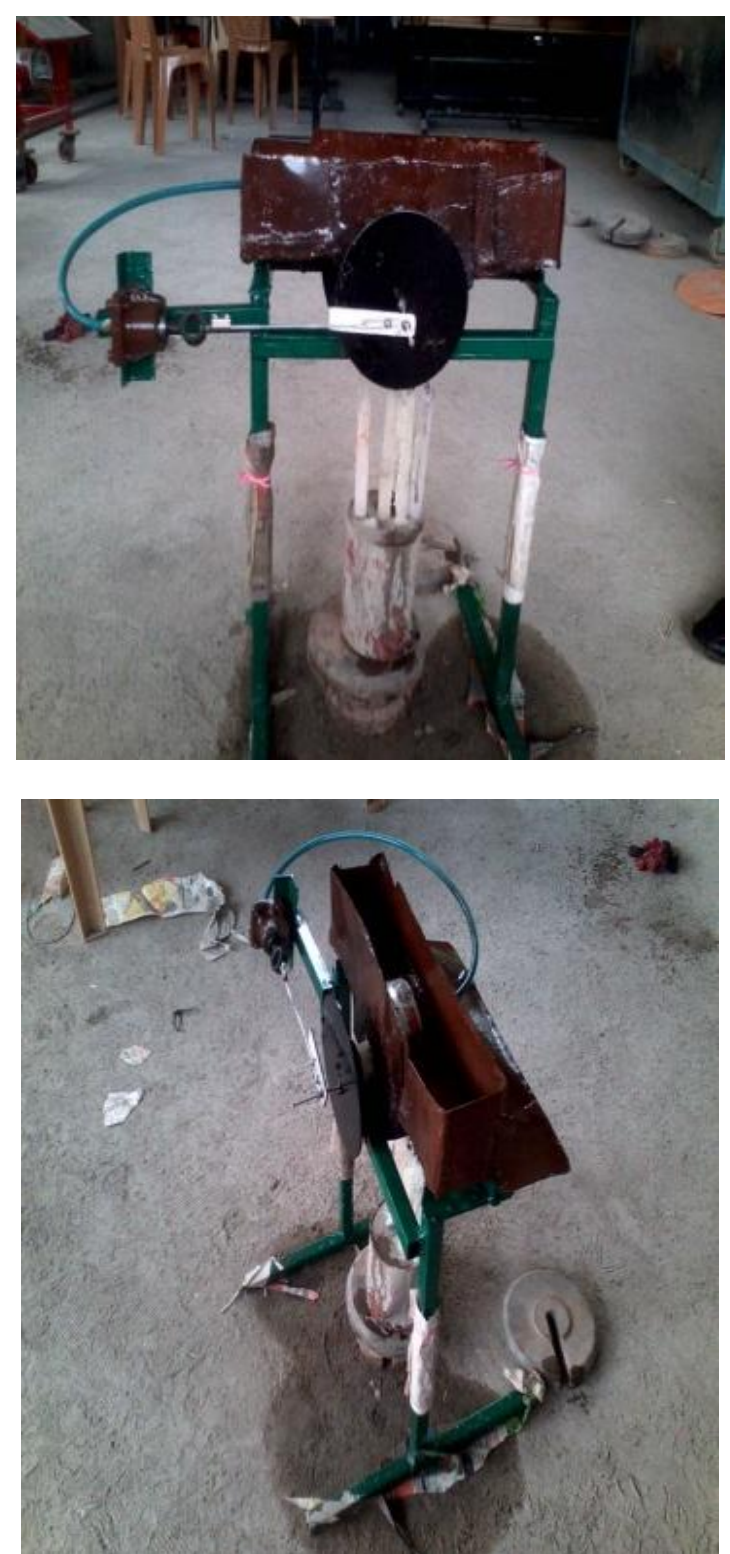

Fabricated Engine
Power Piston Assembly- The power piston assembly is obtained from the compressor of a refrigerator. It is readily available. A hole was provided for connecting the connector and there by pneumatic tube.

Frame- The frame is made up of square G.I pipes. The pipes are cut into various pieces and are welded together with electric arc welding to obtain the desired structure.

Final Assembly- The displacer cylinder and the power piston cylinder are screwed onto the frame. The two cylinders are connected by means of a pneumatic tube which transfers pressurized air. The air inside the displacer cylinder is filled by means of a compressor. A plate is used to separate the two sides of the displacer cylinder which are the hot and cold side. A steel rod is act as a link between flywheel and power piston,

\subsection{Testing Procedure}

After the completion of the fabrication the next methodology was to test the engine to ensure that the engine is functioning as per the design. There were many problems we faced while testing the engine. In each stage of testing advanced thoughts were needed to solve the problems. The testing is to be carried out to ensure a proper working condition of the engine. The procedure for testing the engine is as follows;

At first, the displacer cylinder was made-up of Tin material. The engine is set on the frame and gas flame was used to power the engine and water cooling was applied. Upon heating the displacer cylinder has melted and there were no outputs. Major disadvantage of this material is upon heating the cylinder melts. It is not possible to fill the tin material with pressurized air.

In order to overcome the major disadvantage of tin material we made the cylinder using steel. The material was a low grade steel. The material of displacer has also changed to MSeal from body-filler. Again the heat input was given by gas flame and the same water cooling method is used to cool the top side of cylinder. Since the gas flame is used on low grade steel the cylinder has melted and a small rotation is obtained as output. The rotation of flywheel was not continuous and air-leakage was a main problem. We failed to provide proper sealing on the cylinder. And we couldn't fill the displacer cylinder with high pressure air. 

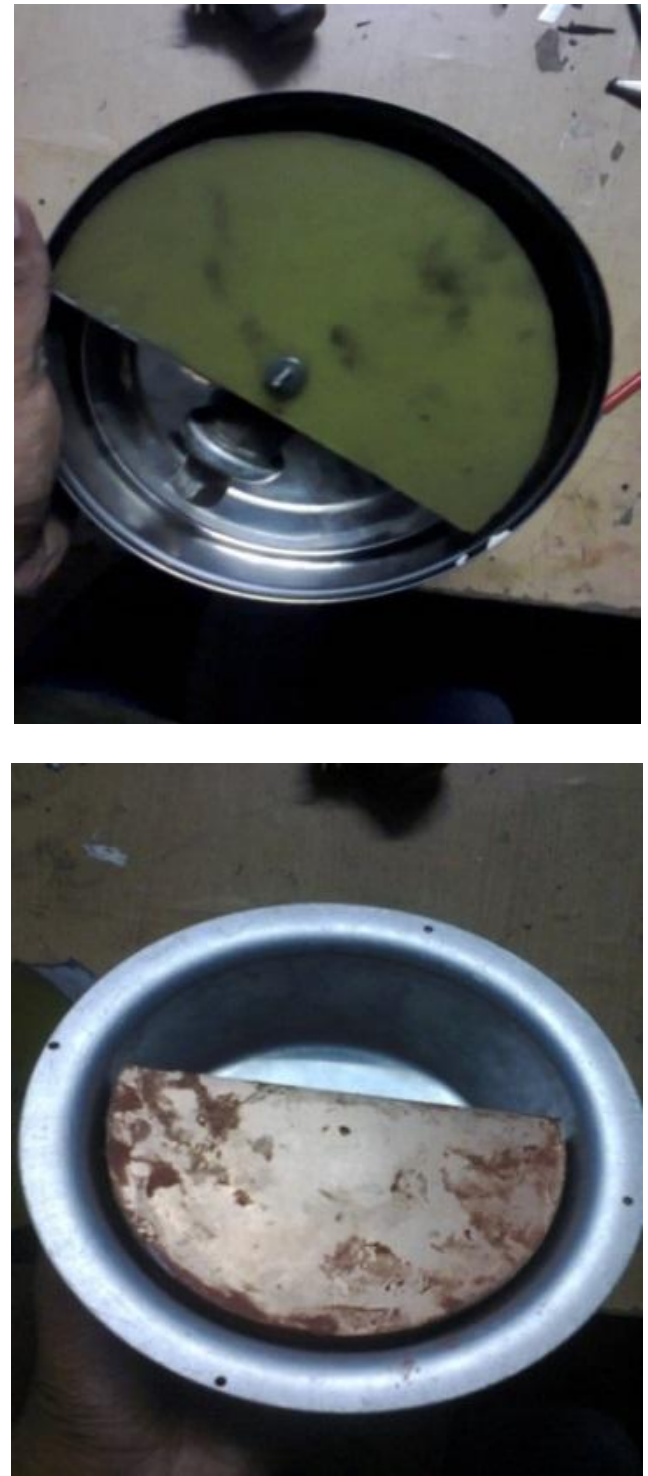

Displacer cylinder made of Steel (1) and Aluminum (2)

Before testing the material of the displacer cylinder is changed to aluminum and the displacer piston is made up of M-Seal and aluminum composite panel. The engine is set on the frame and the heating is done using candles. The candles are not much efficient to provide the sufficient heat input to the engine. The top side of the cylinder is cooled using ice cubes and cold water. In this case also the pressure inside the cylinder was about atmospheric pressure. The amount of heat energy as input can be reduced only when the pressure inside the displacer cylinder is kept as much as higher than atmospheric pressure.

We have tried to increase the pressure inside the displacer cylinder by means of a pump which is used for the tyres of bicycles. The sides of the displacer are closed by means of aluminum plates which are screwed to the cylinder along with M-seal. We failed to create a high pressure inside the displacer cylinder. The leakage of air was a major disadvantage also. Because of these two reasons our engine failed to function properly.

\subsection{Suggestions}

Our engine can be perfectly made to working condition when the displacer piston cylinder is made up of suitable material which will withstand high pressure and proper sealing is provided on the closing sides of the cylinder. If the material used for the cylinder is high grade aluminum then the sealing could be given using gas-welding process. When materials with accurate dimensions are used to fabricate this engine, then the output obtained will be same as that of the design calculations. The efficiency of the engine can be increased when the temperature difference between the two reservoirs are maximum.

\subsection{Future Scopes and Applications}

The Stirling engine can be adopted in various fields of engineering. It is cost effective and the maintenance cost is very low. Working fluid is fixed and there is no need for the continuous supply of working fluid. We have fabricated this engine to consume the waste energy from the steam-boiler accessories of the college canteen. Apart from these simple household applications the Stirling engines can be used in various fields. The major fields of applications of the Stirling engines are cars, submarines, heat and power system, solar energy

\subsection{Summary and Conclusion}

There were many difficulties found while working with all these methods. The results of the above three approaches are as follows: Since the rhombic drive is complex in construction kinematic synthesis was difficult. Scaling down to $1 \mathrm{~kW}$ found to be more complicated because the scaling calculations are much complex. Load calculation is miscellaneous and there wasn't any option to assume the numerical value for some unknowns. The major problem or the dis-advantage associated with the beta-type is the friction on the bush of displacer and the bush for power piston. The working fluid may be leaked from the cylinder of beta type engine. It will affect the exact functioning of our engine because the working fluid is fixed and there is not any continuous supply of the working fluid, and once filled it is fixed.

The gamma type Stirling engine with rotary displacer is a rare type and it is simple in construction. It can be fabricated with much lower cost for the house-hold applications. The waste heat from boilers, furnaces etc can be used to provide the heat input to the engine and thereby utilizing waste heat to produce mechanical or electrical energy as needed.

\section{REFERENCES}

[1]. Operating principles of Stirling engine. Retrieved from http://www.robertstirling engine.com/principles. 2011

[2]. Design analysis methods for Stirling engines. Journal of Energy in Southern Africa, 19(3), 4-19. Snyman, H., Harms, T. M., \& Strauss, J. M. (2008).

[3]. Basic Study on Development of Stirling Engine for Small Portable Generator Hirata, K., Hamaguchi, K. and Iwamoto, 2009 
[4]. Performance Analysis Of A Stirling Engine Heated By Two Individual Heat Sources (Solar And Fossil Fuel), MasoudToughian, Hasan Hacışevki Department of Mechanical Engineering, Eastern Mediterranean University, Salamis YoluMagusa - TRNC, Mersin , 2010

[5]. Heat Recovery Systems by D.A.Reay, E \&F.N.Span, London, 1979.

[6]. Walker G. Stirling engines. Oxford: Clarendon Press, 1980 .

[7]. Senft JR. Ringbom Stirling engines. New York: Oxford University Press, 1993.

[8]. WalpitaSH, 'Development of the Solar Receiver for a Small Stirling Engine', Special study project report no.ET83- 1. Bangkok: Asian Institute of Technology; 1983.

[9]. www.wikipedia.com

[10]. www.stirlingengine.com

[11]. www.youtube.com

[12]. Shah Alam. A proposed Model for Utilizing Exhaust Heat to run Automobile Air conditioner.International Conference on "Sustainable Energy and Environment (SEE 2006)"'.

[13]. M. J. Dadi, I. M. Molvi, A. V. Mehta, The most efficient waste heat recovery device: a gamma type Stirling engine, International journal of advanced engineering technology, January - March, 2012, 189 - 195.

[14]. G. Cronenberg, the Stirling Engine, Uppasala University, 2005.

[15]. B. Kongtragool, S. Wongwises, A review of solar powered Stirling engines and low temperature differential Stirling engine, Science Direct renewable and sustainable energy, 7 ,2003, $131-154$.

[16]. G. Walker, Stirling engine (Oxford Clarendon Press, Calgary).

[17]. W. B. Stine, Stirling Engines, (CRC Press, Boca Raton, 1998). 